\title{
De la indignación
}

falsa a la real.

Consideraciones

entorno al 15-M

español* / From false

to real indignation.

Considerations

around spanish 15-M

movement

* Recibido: 20 de febrero de 2012. Aceptado: 24 de marzo de 2012

Tla-Melaua, Revista de Ciencias Sociales. Facultad de Derecho y Ciencias Sociales. Benemérita Universidad Autónoma de Puebla, México / isss: 1870-6916 / Nueva Época, Año 6 No 32, Abril - Septiembre 2012, PP. 30-45. 
El presente texto es, por un lado, una crónica concienzuda del movimiento 15-M español y, por la otra, una crítica mordaz al desarrollo y devenir del mismo. Si en un primer momento la protesta social del 15-M fue vista como un acto genuinamente democrático; al paso del tiempo las extremas protestas "democráticas" de los indignados terminaron por violar derechos y libertades ciudadanas. La indignación, escribe el autor, si no es concreta, es decir, si no tiene claramente identificado quien(es) la producen, entonces es mera simulación. Para el autor, los verdaderos indignados no so ya los ocupantes de la Puerta del Sol; sino los comerciantes, vecinos y transeúntes de la zona que han sido privados de un verdadero espacio público. Esto es justamente parte fundamental de la crítica moral del autor respecto al 15-M español.

\section{PALABRAS CLAVE}

Movimiento 15-M, democracia española, indignados, ideología, elecciones.
This article is, first, a thorough chronicle of the Spanish 15-M movement and, second, a scathing critique of the development and evolution thereof. If at first the social demonstration of the 15-M was seen as a genuinely democratic act, through the course of time the extreme protesters under the "democratic" cloud of the indignant eventually violated the rights and liberties of the citizens. The outrage, writes the author, if not specific, that is, if not clearly identified who or what (is) the cause, then it is a mere pretense. For the author, the really aggravated and not so occupants of the Puerta Del Sol, but merchants, neighbors and passersby in the area who have been deprived of a true public space. This is just a fundamental part of the author's moral criticism on the Spanish 15-M. KEYWORDS

15-M movement, spanish democracy, outraged, ideology, elections.

\footnotetext{
*** Consejero de Educación de la Embajada de España en México. (agapito.maestre@mecd.es)
} 
I. Para abrir la boca

II. Interpretaciones del 15-M

III. Algo más que un movimiento de oportunistas.

Primera crónica del 15-M

a. Desfondamiento de la democracia. L.D. 18.5.2011

b. ¿Gornada de reflexión? L.D. 20.5.2011

c. 22- y las contradicciones de Sol. L.D. 23.5.2011

d. De la indignación a la violencia. L.D. 9.6.2011

e. La democracia real versus la realidad democrática.

Expansión, 11.6.2011

f. Meditación sobre Sol. L.D. 1.6.11

\section{PARA ABRIR BOCA}

La bestia embiste en línea recta. No sabe caminar zigzagueando; por el contrario, el ser humano da rodeos, habla y piensa antes de dar una opinión. Deberíamos, pues, imitar al hombre que piensa antes que a la bestia que embiste por derecho. También para analizar un fenómeno social, como el del 15-M, hemos de pensarlo. Antes que embestir con un "si" o con un "no", sería bueno pensar a partir de lo que se ha dicho sobre esa ocupación de la Puerta del Sol de Madrid, incluso deberíamos tomar muy en serio a los participantes en esas manifestaciones que fueron retirándose, cambiando su opinión, o combatiendo a medida que pasaba el tiempo de ocupación de un lugar público, e incluso combatiendo la movilización hasta exterminarla. Nacimiento, desarrollo y muerte de un movimiento del que, al final, quizá sólo quede ideología, por desgracia, o una narración decente sobre su devenir para estimular el desarrollo de la democracia.

Hubo gente que, en un primer momento, vio con simpatía a los manifestantes, porque criticaban los fallos del sistema político; pero, cuando vieron que los presentes lesionaban los derechos de los comerciantes de Sol, o impedían que los vecinos de la zona pudiesen transitar libremente por la plaza, dijeron que este movimiento social despreciaba los derechos de las personas. El Movimiento 15-M dejó de ser un símbolo de protesta por los males del sistema político y se convirtió en un mal del sistema, aunque imprescindible para el propio desarrollo del sistema.

Los cabecillas que seguían ocupando ilegalmente la Puerta del Sol mataron la pasión que los movía: la indignación. Los verdaderos indignados pasaron a ser los comerciantes y los transeúntes que eran molestados por los que ocupaban ilegalmente la Puerta del Sol. La pasión de la indignación, esa especie de odio o aversión que la naturaleza ha puesto en el hombre 
contra los que hacen algún mal, desaparece, muere, si perdemos de vista al causante concreto del mal. ¿Quién es el causante concreto del mal que padecen los "indignados"? ¿El sistema?

El sistema es, en mi opinión, cualquier cosa excepto algo concreto. Por el contrario, ¿quién fue el causante directo y concreto de que los comerciantes de Sol no pudieran ejercer libremente su trabajo?, ¿quién fue el causante concreto de que los ciudadanos no pudieran pasear tranquilamente por un espacio público?: Los ocupantes de la puerta del sol. Los manifestantes del 15-M pasaron de ser unos sedicentes "indignados", o falsos indignados, a ser la causa concreta de la indignación de los comerciantes que no podían ejercer su actividad, y de los ciudadanos, que no podían utilizar los espacios públicos.

\section{I INTERPRETACIONES DEL $15-M$}

La complejidad de un movimiento social puede ser interpretada de múltiples maneras. Quizá la más tosca de las interpretaciones sea la ideológica; entiendo por ideología el intento de imponer a otros una opinión subjetiva, arbitraria y engañosa haciéndola pasar por objetiva, justa y verdadera. En mi opinión, la "interpretación” ideológica del 15-M es hegemónica en los ámbitos universitarios y en todas las agencias "culturales" que, desde la década de los 60 hasta la caída del Muro de Berlín, hicieron de la defensa del "marxismo occidental" el principal medios de subsistencia de la llamada "izquierda intelectual."

Naturalmente, ese tipo de interpretación está extendida por todas partes y, especialmente, en España se presenta revestida con el manto de una superioridad "moral" de la que carecerían todos aquellos que no compartieran los motivos de la ocupación, durante meses, de la Puerta del Sol de Madrid. Para que se hagan cargo de la penetración de la ideología de ese tipo de "análisis" en las redes educativas españolas, permítanme que les narre una brevísima historia. Una profesora de Ciencias Sociales de un colegio español, concertado y de ideario católico, le pide a sus alumnos que opinen en su blog sobre el movimiento del 15-M; naturalmente, ella les ha dado su versión afirmativa de la cosa y, además, todos los alumnos tienen que ver un vídeo de José Luis Sampedro a favor del 15-M. La mayoría de los alumnos dan su opinión en el blog de la profesora. Ninguna opinión es censurada, excepto la que escribió un alumno que se negaba a dar su opinión con los argumentos que les cuento a continuación.

No haré la evaluación del movimiento 15-M, decía el alumno censurado en el blog de la profesora, porque carezco de la información necesaria para enjuiciar moral y políticamente esta protesta; además, considero que la información suministrada por la profesora tiene, sin ánimo de ofender, 
cierto sesgo ideológico, porque sólo se nos han presentado las razones de los que están a favor de la protesta. Sería necesario contar con las opiniones de quienes están en contra. El contenido del video a favor del 15-M del señor Sampedro es presentado por la profesora como un "argumento" de autoridad, independientemente de las razones que tenga este señor a favor de la ocupación de unas plazas públicas sin permisos legales. La introducción al vídeo del señor Sampedro que hace la profesora prejuzga, es decir, orienta ideológicamente, por desgracia, al lector.

No seré yo quien descalifique al profesor Sampedro por su trayectoria intelectual, pero tampoco "santificaré" sus opiniones porque alguien me diga que "su pensamiento es comprometido." ¿Qué significa comprometido en esta presentación? Que está a favor de los desposeídos y pobres del mundo o, por el contrario, que está a favor de sus propios intereses personales. Por ejemplo, aquí aporto un artículo sobre el profesor Sampedro que dista mucho de la presentación realizada por la profesora del mencionado escritor. La autoría del artículo citado es de César Alonso de los Ríos. Este trabajo fue publicado en el periódico ABC, el día 8 de agosto de 2011. Quiero hacer una brevísima semblanza de Alonso de los Ríos para que contextualicemos históricamente el texto del autor. César Alonso de los Ríos es un famoso escritor y periodista, autor de una decena de libros, entre los que destacan sus "Conversaciones con Miguel Delibes", "Si España cae" y "La izquierda y la nación". Alonso de los Ríos fue subdirector de la revista Triunfo, durante el franquismo, y director de la revista La Calle en la actual época democrática. Fue un luchador por las libertades contra el régimen de Franco y, por eso, sufrió algunos años de prisión. Pues bien, César Alonso de los Ríos hace una interpretación del "intérprete" privilegiado del 15-M, José Luis Sampedro, que es diferente de la versión ofrecida de la profesora de Ciencias Sociales.

Aquí les dejo, seguía argumentando el alumno censurado, el artículo de Alonso de los Ríos sobre Sampedro para que lo contrasten mis compañeros con la presentación de nuestra profesora. Podría ser un interesante tema de debate futuro: "Los indignados y Sampedro", que es, dicho sea de paso, el título del trabajo de César Alonso de los Ríos. "José Luis Sampedro me ha caído siempre muy bien. A lo largo del franquismo, como catedrático, supo mantener un cierto grado de complicidad con las minorías que estábamos en contra del Régimen. Por supuesto, no participaba en actos críticos y menos en manifestaciones, pero consiguió que fuera conocida su independencia de espíritu. En definitiva, no tuvo el papel de Aranguren o de García Calvo en la movilización de la Universidad, pero supo cultivar en su entorno un espacio crítico bien apreciado por sus colaboradores. Biográficamente utilizaba la seducción de un pasado poco convencional basado fundamentalmente en haber tenido que hacer algunos trabajos para pagarse los estudios y en 
haber escrito una primera novela de tipo sociable nada despreciable. Quizá por todo ello le propuse una entrevista para Triunfo a mediados de los sesenta y quizá también por ello entendí que no quisiera atender mi petición. Laboriosamente había conseguido puestos tan codiciados como formar parte de los Consejos de Administración de algunos Bancos. No tenía que coger taxi o el metro para trasladarse del Banco Urquijo o al Exterior de España. Ya jubilado decidió dejarse la barba y volver a la literatura. Con éxito. La sonrisa etrusca le colocó en el primer puesto de los novelistas más vendidos. Con la transición entró en política y se declaró felipista. Fue con Fernando Claudín la atracción principal del mitin con el que se presentó el PSOE ante el mundo de la cultura. Quizá fue su yerno el que le pidió ese esfuerzo. Por aquella época concedió una entrevista a Ricardo Cid Cañaveral para la revista $L a$ Calle, que le costó a este una rectificación pública: había puesto en boca del entrevistado unas declaraciones sobre Carter hechas off the record. Como director de la publicación di la razón a Sampedro, y mi querido Ricardo escribió unas líneas que nos dejó a todos tan contentos, incluido al embajador norteamericano.

Ahora Sampedro ha puesto el prólogo al respetable panfleto Indignaos de Stephane Hessel, con el que el "pensamiento" francés ha vuelto por sus fueros hegemónicos. Sampedro ha querido expresar su solidaridad con la causa que defiende el autor: ha querido hacer saber que también él comprende las razones de los jóvenes para romper la atonía y la pasividad a las que les está llevando en la práctica el sistema democrático. Mi disentimiento con Sampedro no reside en esa generalización, sino con las declaraciones que hizo, y tal como las hizo, a una emisora de televisión en relación con el ajusticiamiento de Bin Laden: calificó el acto de asesinato y puso el caso como ejemplo de esas cosas insufribles que merecen la indignación de los ciudadanos. Fue en esa ocasión cuando pensé que debía escribir este artículo a pesar de la simpatía que sigo teniendo a José Luis Sampedro.”

\section{I . Algo mÁs QUe un MOVimiento De OPORTUnistas. PRIMERA CRÓNICA DEL $15-M$}

A pesar de las interpretaciones ideológicas de las manifestaciones del 15-M contra el sistema capitalista en general, y la democracia española en particular, nadie saque conclusiones apresuradas sobre mi opinión política de estas movilizaciones que tenían su punto de encuentro real y simbólico en la ocupación de la Puerta del Sol de Madrid (España). Este movimiento de "indignación" social fue, e incluso es, algo más que una protesta liderada por viejos izquierdistas, jóvenes antisistema y viejos oportunistas de antiguas guerras intelectuales para ganar la hegemonía ideológica en el debate político. No me resulta fácil resumir mi opinión sobre este "movimiento" 
social, aún tengo que repensarla con más detenimiento; mientras llegan esas conclusiones, aquí les dejó las crónicas personales que escribí sobre el 15-M en dos periódicos españoles. Todas tienen fecha y, naturalmente, todas ellas incluyen una opinión política.

\section{a. Desfondamiento de la democracia. L.D. 18.5.2011}

Aunque al principio los manifestantes hubieran estado manipulados por los socialistas, o por cualquier oportunista del viejo troskismo español, el movimiento de protesta social contra el sistema político ya está en marcha. El Movimiento de los indignados del 15-M existe. Quizá sea sólo un símbolo, dirán los simples de espíritu, pero un símbolo es el comienzo y el final de toda política. Es menester abrir los ojos y no despreciar lo real. Es en el terreno simbólico, precisamente, donde juegan su partido principal quienes se sienten, y de hecho lo están, excluidos del sistema político. Los excluidos siempre han reaccionado, más o menos, como los del 15-M; ante la proscripción y exclusión de la representación política pública, los excluidos se unen y forman asociaciones independientes de todos los manejos institucionales. Y salen a la calle. A lo que salga.

Desconozco cuántos se unirán a las protestas, e incluso soy incapaz de prever si llegarán a ser más de un millón de personas en toda España; tampoco creo que consigan emular a los resistentes de las plazas de Túnez y el Cairo; pero nada de eso importa ahora. Los manifestantes de la Puerta del Sol levantan, sencillamente, acta del presente político. Dejan con las vergüenzas al aire al PSOE, porque es incapaz de crear un discurso que ilusione, y a IU la ridiculiza, porque pueden mostrar que ellos reúnen en un rato a más gente, véase los concentrados el pasado domingo en la Puerta de Sol, que los dirigentes comunistas en sus mítines perfectamente pagados por el erario público.

Muchos periodistas se toman a broma las manifestaciones de los indignados españoles, peor para ellos, porque demuestran una gran estulticia. No quieren oír el grito de estos "desarrapados", pero es muy sencillo de verbalizar. Los movimientos sociales primarios, y estamos ante uno muy primario, se expresan, sin duda alguna, torpemente, pero con contundencia. Sí, sí, esta gente dice una cosa muy simple y concreta: "Esto no funciona". "La democracia española está muerta".

El 15-M, guste o no guste, es ya un símbolo. Quizá sea el primer símbolo de la muerte de un periodo de la política española; quizá sea el primer reflejo importante de que está agotándose el período político que va de la Transición hasta hoy. He ahí el momento en que llegará al poder un hombre, un político profesional del institucionalismo democrático, que sólo se emociona, según dicen, viendo a los ciclistas subir el Tourmalé. Sin embargo, necesitará toda la pasión democrática del mundo para enfrentarse 
a lo que ha puesto en evidencia el 15-M: España es un Estado fallido, porque el Estado no es capaz de ejercer el monopolio legítimo de la violencia. He ahí el gran trabajo que tienen por hacer quienes se dedican a la política institucional: o hacemos una jerarquía de violencias para plantarle cara o el sistema democrático desaparece.

Es menester adoptar una perspectiva, buscar un lugar o, sencillamente, hacerse un esquema mínimo para acercarnos a las diferentes formas de violencia. El 15-M no es violento, pero ocupa espacios públicos sin ningún tipo de autolimitación. Está en el límite de la violencia física y ejerce una violencia simbólica en sus formas de plantarle cara al sistema. El 15-M ha venido a visibilizar, a sacar a la luz, las contradicciones de un sistema político que está en peligro. La primera y, seguramente más cruel contradicción, es que el Gobierno no sólo no ha ejercido su primera función, es decir, dar seguridad a todos sus ciudadanos a través del uso legítimo de la violencia física, sino que al haber intentado instrumentalizar el movimiento pudiera terminar abrasado. He ahí otra prueba para empezar hablar en serio de un "Estado fallido".

\section{b. ¿fornada de reflexión? L.D. 20.5.2011}

No se preocupen señores políticos por la morralla de Sol. La morrallita, como decía la canción de Carlos Cano, somos todos. También soy yo. A todos nos gustaría estar en Sol, pero, ay, siempre hay un pero... El sistema nos atrapa, incluso a sus críticos más feroces. Y, sin embargo, la movida de Sol sirve para algo. Remueve conciencias. No es poco para quien sigue creyendo en las causas perdidas. Y la actual democracia española, no lo duden, es una causa perdida. Es, sí, una causa moral, o peor, la democracia ha quedado reducida a un asunto moral. A pesar de todo, los ingenuos se preguntan: ¿Se respetará o no la jornada de reflexión del día de las elecciones del 22 de mayo? Inocentes. ¿Qué es eso de la jornada de reflexión? Nada, o peor, una impostura más de algo en lo que nadie cree. El día de reflexión es un adorno ridículo de un sistema político fracasado. A ese sistema le llaman democracia, cuando en verdad es sólo un día para que votemos de forma estabulada. Para los indignados del 15-m las formalidades de la democracia no representa nada, o peor, son otros tantos motivos para manifestarse contra el sistema.

Ahora, unos días antes del 22-M, del día de las elecciones municipales y autonómicas, a los políticos se les llena la boca de algo que desconocen real y sinceramente: la democracia. Ni existen en los partidos políticos ni existe en las instituciones. La mayoría de la casta política está ahí para enriquecerse. Son todos sustituibles. Inservibles. Todo ha quedado reducido a un método para seleccionar a los que previamente han sido nombrados a dedo por el jefe, sirviéndose de una ley electoral injusta y ridícula. Y quizá preconstitu- 
cional. ¿Democracia? ¿Qué democracia es esta basura que deja presentarse a los criminales de ETA a las elecciones? ¿Estado de Derecho?: ¿Qué Estado de Derecho es esto que nos impone las directrices sobre cómo tenemos que leer la historia de España y, sobre todo, adoctrina a nuestros hijos en las peores perversidades y manipula sus afectos más íntimos?

Aunque todavía veremos cosas peores, la cosa está tocando fondo. La intervención de un político populista, como Zapatero, ha sido imprescindible para alcanzar los actuales niveles de degradación del sistema político; naturalmente, sin el acompañamiento de Rajoy, es decir, sin la molicie apolítica del jefe del PP, no hubiéramos llegado a tal degradación. En cualquier caso, las cosas son como son y, por supuesto, podrían empeorar, aunque la casta política lo oculte. La representación política en España, seguirá siendo arbitraria y falsa. Y, por supuesto, el espacio público-político permanecerá secuestrado por los politicastros socialistas, populares y nacionalistas.

¿Qué puede esperarse de un sistema político que permite irse, poco menos que por la puerta grande, al político más cerril y, sobre todo, más totalitario que ha dado este régimen de la Transición? Zapatero se va, sí, y Rajoy ni siquiera ha hecho un amago de moción de censura. El sistema político español toca su fin. Pero, no se preocupe nadie, esto aún durará tiempo. Las elecciones se llevarán a cabo con relativa normalidad. A Esperanza Aguirre, presidenta de la Comunidad de Madrid, a pesar de lo que digan sus cantores, le vendrá bien, muy bien, la concentración que está frente a su despacho. Y aquí paz y después gloria. Tranquilos.

No pasa nada. El 15-M es menos que un movimiento social, sí, es sólo la movida de la Puerta del Sol, una movida madrileña, o sea, un aviso, un alevoso recuerdo a los profesionales de la política, sobre la bajísima calidad de la democracia española.

\section{c. 22-M y las contradicciones de Sol. L.D. 23.5.2011}

Las elecciones del 22-M, sí, han sido muy importantes, pero es obtuso, como mínimo, aislarlas de los últimos sucesos de las concentraciones promovidas por grupos de ciudadanos instalados en la Puerta del Sol y otras plazas de España. Quizá el grupo más numeroso de los del 15-M son antiguos votantes socialistas, y, seguramente, después de una semana de plante, el movimiento social ya esté controlado por dirigentes mayoritariamente de extrema izquierda. Pero, de momento, todo eso es un asunto menor, porque lo decisivo de esta protesta, con todas sus contradicciones y manipulaciones sigue en pie: los españoles no somos borregos, la casta política tiene una gran parte de culpa de todos nuestros problemas y, por supuesto, es menester que el espacio público-político no sea devorado por la clase política. Son necesarias reformas importantes en el sistema político. $\mathrm{O}$ hay regeneración democrática o esto muere. 
Estas elecciones, nos guste o nos disguste, han estado vinculadas a esta protesta, negarlo es estar ciego o, algo peor, sustituir lo real por la ideología, la mentira, que estos mismos "analistas" tratan de ver y, por supuesto, combatir en aquellos que están concentrados en la Puerta del Sol. Basta, por favor, de imbecilidades e ideologías baratas. La movida de Sol ha puesto nervioso a los partidos políticos, incluido el PsoE; más aún, soy de la opinión de que están desbordados en asuntos fundamentales, por mucho que algunos insistan en que la indignación está controlada por las covachuelas del gobierno de Zapatero.

Por otro lado, buena parte de los analistas políticos, especialmente los vinculados a los medios de comunicación de la derecha, están fuera de juego, incluso los que juegan a ser los más radicales, esos que, desde hace años se desgañitan porque la sociedad no se moviliza y el sistema de representación está marchito, ahora, cuando otros que no son de su cuerda lo ponen en evidencia, se asustan y apoyan toda la faramalla sobre la que sustenta la casta política. Esto también es un síntoma del fin de un régimen político que comenzó en la Transición y ya no soporta tanta contradicción.

Por favor, amigos "demócratas", que estáis esperando un carguito para cuando llegue el PP al machito del poder, tened un poco de respeto por lo real. Al menos, por favor, reconocedme que, ayer por la mañana, día de la elección, muchos dirigentes populares estaban perplejos, e incluso algunos se quejaban amargamente de no haber sacado el primer día de la concentración de los indignados, un cartelito desde el viejo edificio de Correos que dijera: "Os entendemos". Por Dios, amigos "demócratas" a la espera de que os nombre algo el PP, cómo no voy a vincular las concentraciones de Sol a las elecciones de ayer y, sobre todo, al futuro del sistema político español. Podéis, naturalmente, negarlo. Allá vosotros, pero estáis haciendo algo peor que el ridículo, negáis vuestra propia identidad de analistas políticos. Si Rajoy y sus seguidores mediáticos no se toman en serio la protesta de la Puerta del Sol, puede que su victoria en votos, del 22-M, se torne en comida para hoy y hambre para mañana. Esa movilización será utilizada en el futuro por el PSOE contra los mesogobiernos del PP, primero, y contra el Gobierno que pudiera formar Rajoy si gana las próximas elecciones generales.

\section{d. De la indignación a la violencia. L.D. 9.6.2011}

Una parte de los indignados del 15-M siguen en Sol. Al toque de silbato, o sea, de movilización por las redes sociales, un millar de indignados fueron el miércoles hasta las puertas del Congreso de los Diputados. No es fácil congregar a un millar de personas, a pesar de que muchos relativicen a este movimiento, para protestar contra la reforma laboral. También se concentraron en otros lugares de España, e incluso hubo cargas policiales y algún herido de cierta gravedad. Sin embargo, todavía hay gente que reduce el 
asunto a poco menos que nada. Se equivocan. Esto va para largo. La ocupación de la Puerta del Sol va para largo. Y, por supuesto, continuamente estará el movimiento del 15-M en el límite con la violencia.

Por otro lado, es natural que el movimiento derive en violencia y enfrentamientos; pues que no se conoce en la historia de la civilización un grupo de individuos que trate de funcionar al margen de la sociedad real sin que ello derive en violencia. Eso es exactamente lo que han hecho los acampados en la Puerta del Sol: ellos han funcionado, y así lo han reflejado todos los comentaristas del mundo, en una plaza pública como una "sociedad" al margen de la sociedad... El enfrentamiento entre dos tipos de sociedades tan diferentes es inevitable.

Pero, independientemente de que nos guste más o menos la evolución de este movimiento social, sin duda alguna, surgido de asociaciones de todo tipo vinculadas a la izquierda y a la extrema izquierda política, es menester reconocer su existencia. Hacerle menosprecio, ridiculizarlo y, sobre todo, no enfrentarlo con medios analíticos es la mejor manera de que nos pase factura. Es evidente que hay dos maneras de hacerse cargo del asunto: por un lado, están los medios de la izquierda que dan una gran importancia al movimiento del 15-M; y, por otro lado, encontramos a los de la derecha que lo relativizan.

Hacen mal unos y otros; los primeros, porque no quieren reconocer la instrumentalización y aliento que les da el ministro del Interior, Pérez Rubalcaba; los segundos, porque le dan al ministro todo el protagonismo del 15-M. Se equivocan todos. Es obvio que Pérez Rubalcaba hace uso, instrumentaliza y alienta el movimiento. Forma parte de su trabajo, sobre todo, después del 22-M. Es su modo normal de hacer política en la Oposición: Hay que agitar a las masas contra los vencedores de las urnas. Pérez Rubalcaba se prepara para la nueva etapa que viene a España. Repito las preguntas formuladas en otro contexto: ¿Por qué el PsoE tendría que reprimir el movimiento del 15-M ahora, precisamente, cuando el PP ha conseguido un poder inmenso en casi todas las Autonomías y Ayuntamientos de España?, ¿por qué Pérez Rubalcaba tendría que ejercer la violencia contra quienes pueden darle votos?, ¿por qué Pérez Rubalcaba va a desalojar de los espacios públicos a un movimiento que surge de asociaciones de extrema izquierda con apoyo de millones de indignados contra el mal funcionamiento de la democracia en España?

El problema ya no es sólo del gobierno socialista. El problema es también del Pp. Es uno de sus grandes problemas. Rajoy es ya un hombre muy poderoso porque su partido tiene un inmenso poder en toda España, y él está llamado a ser el próximo presidente del Gobierno, pero todavía no se ha dignado a decir qué hacer, cómo resolver y, sobre todo, cómo encarar a ese movimiento "político". He ahí el verdadero problema. Rajoy no lo quiere 
encarar ahora, pero, por desgracia, acabará estallándole en el futuro. Será una fuerza de choque que utilice el PSOE contra el PP.

Los manifestantes de la Puerta del Sol, más allá de que estén o no manipulados por el PSOE o IU, mantienen una inspiración común con todos los grupos humanos que en la historia se han movilizado por su libertad: no quieren que el espacio público muera arruinado por la casta política. Ninguno de los que se manifiesta quiere renunciar a ese espacio que le permite participar en la resolución de los diversos conflictos sociales. También este grupo de manifestantes, seguramente de origen izquierdista, que puede ser distinto y hasta contrario a otros que han surgido en los últimos años contra las leyes ideológicas de Zapatero, se movilizan por otro tipo de sociedad, que está lejos de una formulación política clara y distinta, pero que, al menos, se movilizan porque todos los ciudadanos tengan acceso a lo público con el mínimo de cortapisas posibles. En otros términos, creen que la democracia no empieza ni acaba con la mera elección. Esta protesta de la Puerta del Sol, como otras que han surgido contra los políticos profesionales, es otro aviso, o mejor, un recuerdo sencillo: la sociedad civil podría ser capaz de gobernarse a sí misma sin necesidad de parásitos del institucionalismo político.

\section{e. La democracia real versus la realidad democrática. Expansión, 11.6.2011}

Las concentraciones del 15-M han dejado tocados y, a veces, fuera de juego a los políticos y a los periodistas. Y, por supuesto, a los grandes ejecutivos de las principales corporaciones españolas. Este movimiento es demasiado importante para no comentarlo con detenimiento. Quienes desprecian su importancia, en mi opinión, niegan lo real. Caen en la ideología que tratan de combatir en los manifestantes. Más aún, este movimiento social irá, por supuesto, cambiando también en función de los análisis y teorizaciones que de él se hagan. No nos engañemos. Prestemos atención a lo que dicen y hacen. Y, por supuesto, leamos con detenimiento las interpretaciones. De momento, y no es poco, resulta un movimiento pacífico de primera magnitud, que ha conseguido abrir las elecciones del 22-M a una nueva interpretación. Los resultados electorales, cómo no reconocerlo, también han estado influidos por los movimientos del 15-M, que influirán sin duda alguna en la política futura de España.

Pero, antes de analizar los resultados electorales en función de las concentraciones de Sol, es menester resaltar que resulta triste constatar que la reacción de la prensa y los medios en general ante las concentraciones de este mayo electoral ha estado por lo general tan ideologizada como el resto de la vida española. En esta perspectiva ideológica, hay que reconocer que el socialismo que nos gobierna ha hecho un buen trabajo de zapa en la mentalidad de los españoles de ambos sexos, hasta reducir al mínimo las posibilidades de entendernos en un lenguaje común. Falso sería, sin embargo, 
no admitir que el PSOE ha estado muy bien acompañado por el PP en este camino de ideologización y de mentiras, por ejemplo, ¿conoce alguien las propuestas de regeneración política y democrática del PP? La oposición en materia democrática del PP al PSOE dista de ser calificada de eficaz e inteligente en esta materia.

Esa ideologización extrema de la vida política española es una evidencia más de la imposibilidad de entenderse que nos sale al paso a la hora de sacar alguna lección de lo que pasa en la calle, en la Puerta del Sol y otras plazas de España, y lo que dice la gente en estos días a propósito de aquello que empezó a ocurrir en el centro del centro de España. En lo que a los medios de comunicación se refiere, es curioso contrastar ambos lados del frente ideológico vigente, para ver cómo dicen lo mismo para esconder lo que ocurre y jugar cada uno al juego en el que cree poder ganar. En la trinchera de la izquierda domina un tono descriptivo que roza la neutralidad, tal vez porque están convencidos de que toda agitación social les pertenece de pleno derecho, de modo que no hay porqué gastar salvas en reivindicar lo que todo el mundo debe ver con evidencia, a saber, que la contestación social sólo tiene un curso posible que es el de volver al redil de los partidos de la zona del espectro que naturalmente tiene el cometido guiar estos movimientos.

El gesto paternal de Zapatero ante el movimiento 15-M es normal y, por otro lado, es lo que cabe esperar de sus entendederas políticas, limitadas, como se sabe, pero de gran eficacia ideológica. Estamos ante un populista en horas bajas. Pero, curiosamente, desde enfrente responden medios y oposición con la misma afirmación de la naturaleza izquierdista del movimiento, con el solo añadido, que ellos creen fundamental, de que se trata de una manipulación completamente inadmisible que pone en cuestión el Estado y toda su maquinaria legal. Realmente no hace falta. El Estado y su maquinaria están ya en cuestión hace tiempo. No es el ánimo de mediar lo que nos lleva a escribir estas líneas, sino el de disentir de estas maneras tan pobres de ver las cosas, que nos parecen de una ceguera culpable en un asunto de tanta gravedad.

Querer apropiarse de un movimiento así por motivos estético-ideológicos como pretende el PSOE o pasarlo por un ejército de antidisturbios aplicando una legislación que está lejos de ser clara al respecto nos parece la misma barbaridad, cómplice de un sistema político que lleva un país a la bancarrota. Las responsabilidades de uno y otro bando no son ciertamente las mismas: son infinitamente más graves las de un gobierno que ha hecho de la mentira y la ideología guerracivilista un arma letal de desintegración política de la que es posible que España no se recupere. Pero no podemos olvidar las responsabilidades de una oposición que no ha dejado claro, entre otros asuntos, que en sus filas no puede caber ni la más remota sospecha de 
corrupción, que ha dejado pasar ocasiones importantes para plantar cara al gobierno y que ha abandonado prácticamente la nación a las Autonomías y sus derivas nacionalistas más extremas y ridículas. Pero esto es otra historia. De lo que aquí se trata es de afinar el juicio sobre los acontecimientos en cuestión tal como está sucediendo, de los que afirmamos, de entrada, su indeterminación y sus posibilidades abiertas.

Hay, en efecto, algo que está todavía por expresar para que demos de manera firme nuestro apoyo a esa iniciativa que hasta ahora permanece en una incertidumbre que desafía a quien quiera mirar con atención y sin prejuicio. Esa indeterminación nos lleva más allá de los orígenes del movimiento, tal vez fraguado en las covachas de unos pintorescos personajes de nula representatividad política. No es importante. Lo cierto es que lo que hay ahora en la Puerta del Sol no coincide con ninguna configuración ideológica conocida, es decir, ha saltado los límites que los nostálgicos izquierdistas de salón preveían para su mayo revolucionario. Y es aquí donde queremos poner el dedo para señalar las insuficiencias democráticas graves que observamos en esta gente que se define como demócrata real. Nos preguntamos si esa democracia que reivindican no tiene algo de imaginario, en la medida en que no se hace cargo de aquello que le puede dar justamente más realidad. Nos preguntamos cómo es posible que se obvie, o peor, que se oculte, justamente la condición de españoles de ambos sexos, de la ciudadanía española que comparten, en virtud de la cual tienen sentido sus reivindicaciones, pueden exigir a gritos y con razón sus derechos, reclamar su representación, denunciar abusos y corrupciones. En fin, nos preguntamos cómo es posible que se exhiban artículos de una Constitución sin reconocer que es justamente la de un país concreto, con una historia triste y única de odios civiles como recuerda Payne, que se la dio en un acto soberano para encauzar una reconciliación que superara las diferencias asesinas en un régimen de derechos y libertades sólido y duradero. ¿Por qué ocultan los indignados del 15-M que España es un Estado-nación? ¿Por qué no dejan estar con ellos a las personas que se manifiestan con la bandera de España y sin con la bandera contra constitucional de la Segunda República que trajo la Guerra Civil?

Sin España carecen de sentido las expectativas de prosperidad libre y protegida por leyes; en efecto, sin España desaparece la esperanza de transformar estas mismas leyes en el sentido de promover la legítima aspiración a participar en esa libre igualdad; sin la ciudadanía española no habrá sentido para los gritos y protestas que escuchamos en las plazas de España. Sobre todo cuando es una pésima gestión del Estado lo que ha llevado a tanta ruina y desesperación. De otro modo, es cuestión de preguntarse por qué no hacen esas protestas delante del edificio de la ONU o cualquier otro organismo de pretensiones o competencias cosmopolitas. Así pues, he ahí el 
primer déficit de democracia en los enrages de Sol. Un déficit de patriotismo que, de no ser por la triste manipulación ideológica del lenguaje que hace que en español "república" se identifique no con un régimen de libertades, sino con un triste momento de la historia española, llamaríamos con gusto "patriotismo republicano".

Y ya puestos a preocuparse por la salud de la democracia o su realidad como quieren reclamar, no es difícil encontrar un segundo y terrible déficit. Parecen olvidarse estos indignados, entre los que nos sorprende algunos oportunistas con sus firmas, que en este país hay ciudadanos de ambos sexos que no pueden vivir con la libertad que tan fieramente solicitan en Sol con apoyo mediático quizá desproporcionado a su número. La gente asesinada por ETA por el simple y sencillo delito de ser ciudadanos españoles no parece inquietar a nadie de los que están reunidos en Sol; las víctimas del terrorismo de ETA no aparecen en sus reivindicaciones, donde por lo demás figuran tonterías de rango planetario como las que conciernen a la Iglesia. Si se repararan estas deficiencias, sin necesidad de grandes exhibiciones patrióticas ni manifestaciones plañideras, sino por los sencillos medios simbólicos disponibles, estamos seguros de que la solidaridad de los indignados crecería y su clamor ya no podría ser obviado por los partidos de turno.

Bastaría con resaltar que la ciudadanía es española o no es, junto al recuerdo de los asesinados por ETA sólo por ser españoles, para que millones se sumasen a estas protestas.

\section{f. Meditación sobre Sol. L.D. 1.6.11}

Los indignados del 15-M llevan quince días ocupando la Puerta del Sol. ¿Qué decir de su indignación? Ahí va mi meditación: Nunca ha sido fácil hacer un buen uso de las pasiones, especialmente si pertenecen al género de las llamadas pasiones políticas. He ahí el ejemplo de la movida española de los indignados del 15-M, que ha pasado de ser una fuente de inspiración de protesta democrática, sensata y verosímil contra un régimen político mortecino, a una mascarada ideológica para esconder vicios mentales de una vieja y vulgarísima extrema "izquierda" llena de estulticia intelectual y carente de mediaciones democráticas para participar en el sistema democráticos con algún viso de éxito. Por fortuna, los mejores que había en Sol ya se marcharon. Sólo queda la espuma. Permanece una pequeña muchedumbre que hace mal, mucho mal, como diría Descartes, por poseer un bien que no merecen.

La indignación, la ira y la rabia son pasiones valiosas en la medida que están fundamentadas sobre una opinión política, sensata y ajustada a la realidad, unos argumentos sólidos, capaces de enfrentarse a la injusticia de modo proporcionado con el mal causado, y un juicio político, basado en el contraste de muchos pareceres. La pasión de la indignación, esa especie de 
odio o aversión que la naturaleza ha puesto en cada uno de nosotros con mayor o menor abundancia, contra los que hacen algún mal, sea del tipo que sea, desaparece, si perdemos de vista al causante concreto de mal. Eso es, exactamente, lo que ha sucedido en la movida de Sol.

Quienes se han plantado en Sol, sin otro "fundamento" que reclamar una justicia universal contra todos los males de la humanidad, son unos impostores, o peor, gente que se auto-engaña cobardemente. Son, sí, criminales de una de las principales pasiones del ser humano: la indignación, rabia, ira u odio que sentimos por naturaleza contra los que hacen algún mal. Eso es, repito, lo que yo siento ante los concentrados de la Puerta del Sol: indignación. Me siento indignado con ellos porque poseen un bien que no han merecido, a saber, participar en el proceso político de creación de bienes en común sin ninguna limitación, o sea, sin atender que su ocupación de un espacio público era simbólica o se convertía, directamente, en una agresión al resto de ciudadanos que viven en ese lugar.

Mis amigos de Sol, sí, los kiosqueros, los pasteleros, los camareros, los joyeros, los loteros y otros tantos profesionales del sector servicio, se sienten maltratados. Los "indignados" del 15-M han machacado sus negocios. En fin, mientras que la indignación de los comerciantes y ciudadanos de Sol está justificada, entre otras razones, porque el causante del mal está bien delimitado, la indignación de los acampados allí es pura filfa. En efecto, la indignación fundamentada sobre una abstracción, por ejemplo, sobre un sentimiento de injusticia universal, es, en verdad, un engaño. Una manera de asesinar una de las grandes pasiones políticas de todos los tiempos.

Cuando los del 15-M salieron a la calle indignados por la corrupción, o por la falta de representatividad democrática de nuestro sistema político, fueron vistos con simpatías por millones de ciudadanos que compartían esa pasión. La ocupación de un espacio público para convertirlo en un foro político de carácter simbólico fue bien visto por la inmensa mayoría de los ciudadanos. Sin embargo, la ocupación material e ininterrumpida de ese ámbito público por unos cuantos individuos, que incluso reconocen no representarse a sí mismos, tiene que ser vista como una agresión. ¿Qué hacer ante el agresor? Defenderse. O sea, o el ministro del Interior, Pérez Rubalcaba, los desaloja o diremos que está colaborando con los delincuentes.

Lo dicho, querido lector, cuando la indignación no es concreta es mera simulación. Quizá acabe en eso el 15-M. Quizá se convierta en una mera caricatura de una protesta que tuvo un origen genuinamente democrático. Seguiremos. 